\title{
Basal Transcription Factor 3 Plays an Important Role in Seed Germination and Seedling Growth of Rice
}

\author{
Wenyi Wang, ${ }^{1}$ Mengyun Xu, ${ }^{1}$ Ya Wang, ${ }^{1}$ and Muhammad Jamil ${ }^{1,2}$ \\ ${ }^{1}$ Institute of Crop Science, College of Agriculture and Biotechnology, Zhejiang University, Yu-Hang-Tang Road 388, \\ Hangzhou 310058, China \\ ${ }^{2}$ Department of Biotechnology and Genetic Engineering, Kohat University of Science and Technology, Kohat 26000, Pakistan
}

Correspondence should be addressed to Muhammad Jamil; dr.jamil@kust.edu.pk

Received 30 January 2014; Revised 14 April 2014; Accepted 28 April 2014; Published 29 May 2014

Academic Editor: Henry Wong

Copyright (C) 2014 Wenyi Wang et al. This is an open access article distributed under the Creative Commons Attribution License, which permits unrestricted use, distribution, and reproduction in any medium, provided the original work is properly cited.

\begin{abstract}
BTF3 has been recognized to be involved in plant growth and development. But its function remains mostly unknown during seed germination and seedling stage. Here, we have analyzed OsBTF3-related sequences in Oryza sativa L. subspecies, japonica, which resembles with the conserved domain of a nascent polypeptide associated complex (NAC) with different homologs of OsBTF3 and human BTF3. Inhibition of Osj10gBTF3 has led to considerable morphological changes during seed germination and seedling growth. Germination percentage was not influenced by the application of $\mathrm{GA}_{3}, \mathrm{ABA}$, and $\mathrm{NaCl}$ but all concentrations caused wildtype (WT) seeds to germinate more rapidly than the RNAi $\left(O s j 10 g B T F 3^{\mathrm{Ri}}\right)$ transgenic lines. Seedling inhibition was more severe in the $O s j 10 g B T F 3^{\mathrm{Ri}}$ seedlings compared with their WT especially when treated with 100 or $200 \mu \mathrm{M} \mathrm{GA}_{3} ; 50 \%$ reduction in shoots was observed in $O s j 10 g B T F 3^{\mathrm{Ri}}$ seedlings. The expression of $O s j 3 g 1 B T F 3, O s j 3 g 2 B T F 3$ and $O s j 10 g B T F 3$ was primarily constitutive and generally modulated by $\mathrm{NaCl}, \mathrm{ABA}$, and $\mathrm{GA}_{3}$ stresses in both $O s j 10 g B T F 3^{\mathrm{Ri}}$ lines and WT at the early seedling stage, suggesting that Osj3g1BTF3 and Osj10gBTF3 are much similar but different from Osj3g2BTF3 in biological function. These results show that OsBTF3 plays an important role in seed germination and seedling growth gives a new perception demonstrating that more multifaceted regulatory functions are linked with BTF3 in plants.
\end{abstract}

\section{Introduction}

Different transcription factors (TFs) play an important role in multiple physiological mechanisms such as cell cycle progression, metabolism, growth, development, and reproduction [1, 2]. Among these TFs, the basal transcription factors 3 (BTF3) is one of the extremely important transcription factors due to their role in various biotic and abiotic stress processes [3-6] and different physiological and developmental mechanisms such as ionic homeostasis [7], photosynthetic rate [8], and pollen development [6] in plants.

BTF3 was basically found in HeLa cell that is essential for RNA polymerase II dependent transcription [9]. The BTF3 codes two isoforms, BTF3a and BTF3b, in the human, as an outcome of alternative splicing. BTF3a encodes for a protein with complete characteristics of BTF3 and stimulates transcription, while BTF3b encodes a shortened form of $\mathrm{BTF} 3 \mathrm{a}$, as it is missing the first 44 amino-terminal extension.
Afterward, BTF3b was documented as a component of the nascent polypeptide associated complex (NAC). It consists of two subunits, that is, $\alpha$ NAC and $\beta$ NAC [10]. BTF3 is a $\beta$ subunit of the NAC that has been participating in regulating protein localization during translation [11].

BTF3 in plant lacks the N-terminals which exist in the human BTF3a form. But, the N-terminals extension of the plant proteins interacts with that of the transcriptionally dormant BTF3b isoform [12]. In Arabidopsis, AtBTF3 coincides with the translation initiation factor (iso) $4 \mathrm{E}$ (eIFiso4E) and formed the translation initiation complex eIF(iso)4F [12]. NbBTF3 silenced plants show an abnormally developed phenotype in Nicotiana benthamiana. Similarly, in TaBTF3-silenced wheat transgenic plants, Ma et al. [13] demonstrated that the transcripts of the mitochondrial and chloroplast encoded genes were noticeably decreased. In Capsicum annuum, BTF3 gene was observed to play a role in hypersensitive response (HR) cell death and might function 
as TFs in the nucleus via transcriptional regulation of HRrelated gene expression [14].

Recently, in rice, Wang et al. [6] have demonstrated that BTF3 plays important role in plant growth and development. However, the function of different variants of OsBTF3 in seed germination and seedling growth is not yet documented. In the present work, a cDNA sequence of a BTF3-like gene (Osj10gBTF3) was extracted, and its function examined via transgenic strategies to recognize the role it played in seed germination and seedling growth in rice. We also attempt to investigate that how the OsBTF3s were transcriptionally regulated by salt, $G_{3}$, and $A B A$ stresses during seed germination and seedling stage in $O s j 10 g B T F 3^{\mathrm{Ri}}$ lines and wild type.

\section{Materials and Methods}

2.1. Isolation of Osj10gBTF3 and Generation RNAi Repression Lines. RNAs extractions, the full length of cDNA synthesis, were carried out using the BTF3 gene-specific primers via procedures as described by Wang et al. [6]. The amplified products of cDNA were cloned into a pMD18-T vector (TaKaRa). RNAi repression vector was constructed as suggested by Wang et al. [6]. The resultant vector was incorporated into the EHA105 (A. tumefaciens strain), which was used to infect rice embryogenic calli raised from mature seeds of Nipponbare to produce transformed calli. Transformants were screened using primers specific for the hygromycin B phosphor transferase gene $(H p t)$ by PCR amplification as demonstrated by Wang et al. [6].

2.2. Seed Germination and Seedling Growth. Seeds of $\mathrm{T}_{1}$ Osj10gBTF3 ${ }^{\mathrm{Ri}}$ and wild-type (WT) of Oryza sativa L. subspecies japonica line Nipponbare were germinated on double filter paper in Petri plates treated with 0 (distilled water), 50 and $100 \mathrm{mM} \mathrm{NaCl}, 100$ and $200 \mu \mathrm{M} \mathrm{GA}$, and 5 and $10 \mu \mathrm{M}$ ABA. The seeds were incubated at $30 \pm 2^{\circ} \mathrm{C}$ in dark condition in growth chamber. Seed germination was counted at an interval of 12 hours up to 7 days, up to emergence of $\sim 2 \mathrm{~mm}$ radical and germination percentage was calculated when there was $50 \%$ of seed germination. Seedlings after 15 days were taken and separated into shoots and roots for measuring root and shoot lengths.

\subsection{RNA Isolation from Different Tissues. RNA was extracted} from the fresh roots and shoots of Osj10gBTF ${ }^{\mathrm{Ri}}$ lines and WT under normal and stress conditions with Trizol reagent (Invitrogen) by following the manufacturer's instructions. Full length of cDNA synthesis of first-strand was done with the M-MLV first-strand synthesis system.

2.4. Expression Analysis Using Real-Time PCR. To check the expression of Osj3g1BTF3, Osj3g2BTF3, and Osj10gBTF3, real-time quantitative PCR (q-PCR) was used. The target gene names and their primers for the q-PCR are listed in Supplementary Table 2 (see Supplementary Material available online at http://dx.doi.org/10.1155/2014/465739). Q-PCR was done using the method of Wang et al. [6]. The relative expression levels of Osj3g1BTF3, Osj3g2BTF3, and Osj10gBTF3 in root and shoot were calculated using the $2^{-\Delta \Delta C_{T}}$ method [15]. Here, $\Delta \Delta C_{T}=\left(C_{T \text { (Target,test) }}-C_{T \text { (ubiquitine,test) }}\right)-$ $\left(C_{T \text { (Target,calibrator) }}-C_{T \text { (ubiquitine,calibrator) }}\right)$. The $C_{T}$ (cycle threshold) value was the average value of the three different independent samples for both target and reference genes.

2.5. Statistical Analysis. The data were analyzed by oneway analysis of variance (ANOVA), and mean values were separated by least significant difference (LSD) at the $5 \%$ and $1 \%$ probability level using Statistical software (Sigmaplot 10.0.). Sequences of different variants of OsBTF3 were aligned by using ClustalX, while MEGA 5.0 was used for construction of phylogenetic tree.

\section{Results}

3.1. OsBTF3 Sequence and Phylogenetic Tree. The protein sequences of different variants of OsBTF3 were aligned with the related sequences from Arabidopsis (AtBTF3, AEE29647), wheat (TaBTF3, AFV31408), sorghum (SbBTF3, EER93008), maize (ZmBTF3, ACG28870), Ricinus communis (RcBTF3, EEF34688), Capsicumvannum (CaBTF3, ABM55742), Solanum lycopersicum (SlBTF3, NP_001234229), and Nicotiana benthamiana (NbBTF3, ABE01085) (Supplementary Table 1). Protein sequence analysis showed that different variants of OsBTF3 such as Osj10gBTF3 and Osj3g1BTF3 contained a putative mitochondrial matrix targeting sequence (MMTS) (residues 1-15, MNVDKLKKMAGAVRT), a putative nuclear localization signal (NLS) (residues 22-25, RRKK), a conserved NAC domain (residues 33-97), and a putative ER-retention/retrieval signal (ERRS) (residues 161-164, AEEK), while Osj3g2BTF3 lack MMTS or ERRS (Figure 1(a)). It means that these two genes having different genomic loci are either cytosolic or a nucleus proteins. These results show that $O s j 10 g B T F 3$ and $O s j 3 g 1 B T F 3$ are probably differing from $O s j 3 g 2 B T F 3$ in subcellular localization and other biological function.

Phylogenetic analysis (Figure 1(b)) was performed between different variants of OsBTF3 and BTF3-like members from other plant species. The analysis showed that Osj10gBTF3 is more strongly associated to Osj3g1BTF3, followed by other BTF3 homologs of the plant species. The BTF3 homologs of monocot and dicot species form different clades. Additionally, Osj3g2BTF3 has a closer association to the homologs of dicot species AtBTF3 and RcBTF3 than Osj3g1BTF3 and Osj10gBTF3. These results indicate that there may be functional variation between Osj3g1BTF3, Osj10gBTF3, and Osj3g2BTF3 of BTF3 proteins.

\subsection{Inhibition of Osj10gBTF3 Causes Phenotypic Changes.} The functional analysis of BTF3 was investigated using repression and overexpression strategies. Different independent Osj10gBTF3 overexpressed lines were produced before the application of the RNAi construct for functional analysis of Osj10gBTF3 using the overexpression constructs. But most of these lines did not show any significant change in phenotype; therefore, we mainly focused on RNAi inhibition analysis. Osj10gBTF3 ${ }^{\mathrm{Ri}}$ transgenic seeds were investigated 


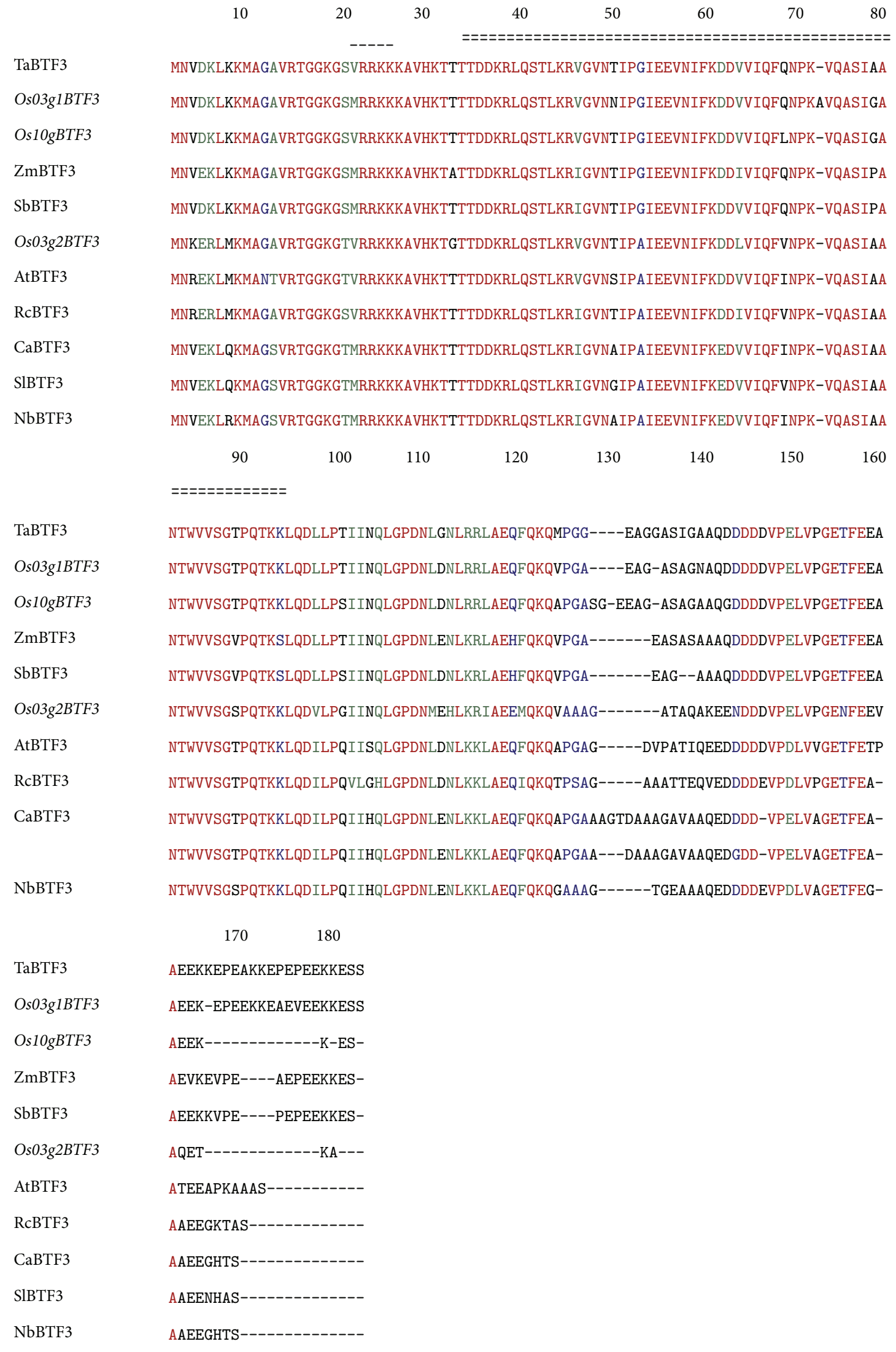

(a)

FIgure 1: Continued. 


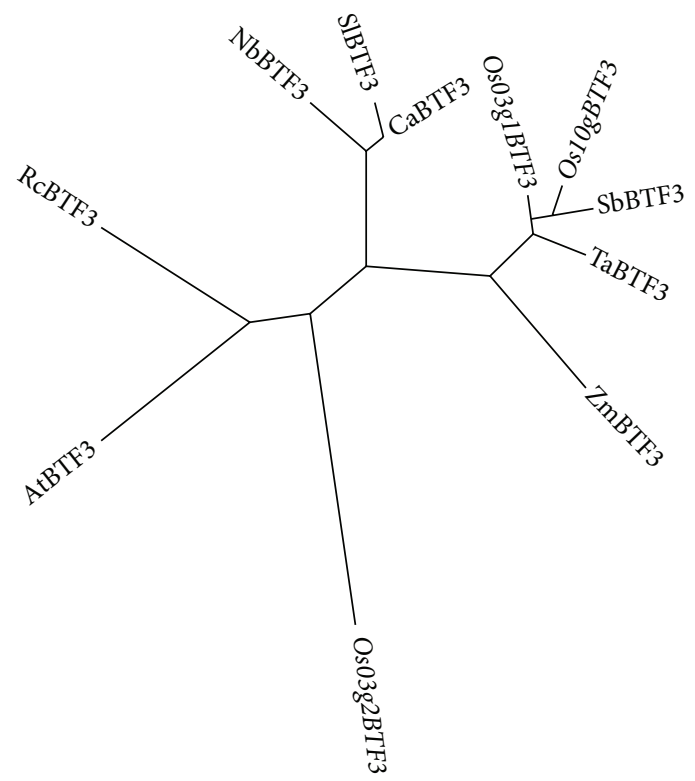

$\mid 0.01$

(b)

Figure 1: Amino acid sequence comparison (a) and phylogenetic tree (b) of different variants of OsBTF3. A deduced amino acid sequence of different variants of OsBTF3 and alignment with related sequences of different plants. The residues conserved among the compared sequences are in red colour. The overline (---) indicates a putative nuclear localization signal sequence, while the double dashed line (==) indicates the NAC domain. Gene Bank accession numbers for the proteins in the alignment are as follows: Arabidopsis thaliana BTF3 (AEE29647), Nicotiana benthamiana BTF3 (ABE01085), Oryza sativa 10gBTF3 (NP_001064883), Oryza sativa 3g1BTF3 (NP_001048709), Oryza sativa 3g2BTF3 (NP_001051911), Capsicum annuum BTF3 (ABM55742), Ricinus communis BTF3 (EEF34688), Solanum lycopersicum BTF3 (NP_001234229), Triticum aestivum BTF3 (AFV31408), Zea mays BTF3 (ACG28870), and Sorghum bicolor BTF3 (EER93008). The tree was constructed using MEGA5 software.

for their capability to germinate, mainly in the presence of different concentrations of $\mathrm{GA}_{3}, \mathrm{ABA}$, and $\mathrm{NaCl}$. Though the final germination percentage was not affected by the application of $\mathrm{GA}_{3}, \mathrm{ABA}$, and $\mathrm{NaCl}$ but all the levels of $\mathrm{GA}_{3}, \mathrm{ABA}$, and $\mathrm{NaCl}$ caused WT seeds to germinate more rapidly than the $O \operatorname{sj} 10 g B T F 3^{\mathrm{Ri}}$ transgenic lines and their mean germination rate reduced with increased $G_{3}, A B A$, and $\mathrm{NaCl}$ concentrations (Figure 2). It is worth mentioning here that the decrease in germination rate was more severe in the $\mathrm{GA}_{3}$ treated seeds as compared to $\mathrm{ABA}$ and $\mathrm{NaCl}$. These results demonstrate that $O s j 10 g B T F 3^{\mathrm{Ri}}$ transgenic lines are more sensitive to $\mathrm{GA}_{3}$ than $\mathrm{ABA}$ and $\mathrm{NaCl}$.

The seedling growth of WT and $O s j 10 g B T F 3^{\mathrm{Ri}}$ lines showed a different trend of variations in response to $\mathrm{GA}_{3}$, $\mathrm{ABA}$, and salt treatments (Figure 3 ). The root and shoot lengths decreased in response to increasing concentrations of $\mathrm{ABA}$ and $\mathrm{NaCl}$ (Figure 4). However, $\mathrm{NaCl}$ had a more negative effect on root and shoot than ABA. On the other hand, $\mathrm{GA}_{3}$ did not induce significant changes in root with increasing concentration of $\mathrm{GA}_{3}$; however, a considerable increase in the shoot was observed with the increasing level of $\mathrm{GA}_{3}$. It was worth observing that the repression was more serious in the $O s j 10 g B T F 3^{\mathrm{Ri}}$ seedlings compared with their WT. When treated with 100 or $200 \mu \mathrm{M} \mathrm{GA}_{3}, 50 \%$ reduction in shoots was observed in $O s j 10 g B T F 3^{\mathrm{Ri}}$ seedlings compared to their WT (Figure 4). However, shoot length was increased in Osj10gBTF3 ${ }^{\mathrm{Ri}}$ seedlings when treated with $50 \mathrm{mM} \mathrm{NaCl}$. These results demonstrate that inhibition of BTF3 caused significant phenotypic changes during seed germination and seedling growth; however, these changes were more serious when treated with $\mathrm{GA}_{3}$ as compared to $\mathrm{ABA}$ and $\mathrm{NaCl}$.

To assess whether these phenotypic changes in $O s j 10 g B T F 3^{\mathrm{Ri}}$ seedling were caused by RNAi inhibition, real-time quantitative PCR analyses were carried out using the OsBTF3-specific primers (Supplementary Table 2) to check the regulation of different variants of OsBTF3 in root and shoot at seedling stage under ABA (5 and $10 \mu \mathrm{M}), \mathrm{GA}_{3}$ (100 and $200 \mu \mathrm{M})$, and (50 and $100 \mathrm{mM}$ ) salt stresses. The ubiquitine mRNA level was used as a positive control.

The results showed that the expression of Osj3g1BTF3 was induced by low and high concentrations of $\mathrm{GA}_{3}$ in root and shoot but was repressed by high concentrations of $\mathrm{GA}_{3}$ in shoot (Figure 5). In contrast, the number of transcripts increased with $\mathrm{GA}_{3}$ in $O s j 10 g B T F 3^{\mathrm{Ri}}$ seedling at $100 \mu \mathrm{M}$ but decreased at higher concentrations. In $O s j 3 g 2 B T F 3$, samples treated with $100 \mu \mathrm{M} \mathrm{GA}$ had less transcripts compared with controls in root. However, the transcript level significantly increased in root and shoot at 100 and $200 \mu \mathrm{M}$ 


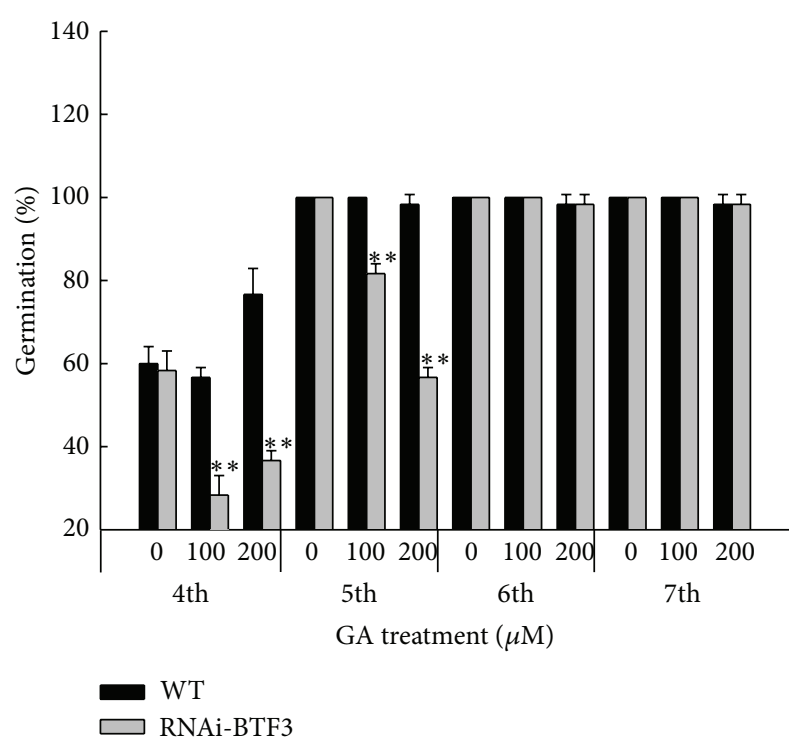

(a)

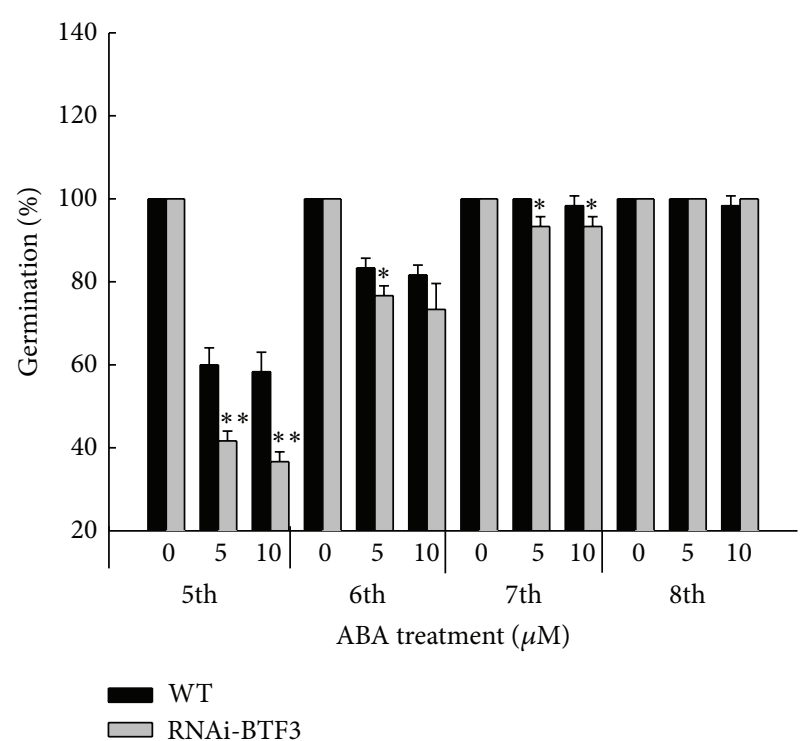

(b)

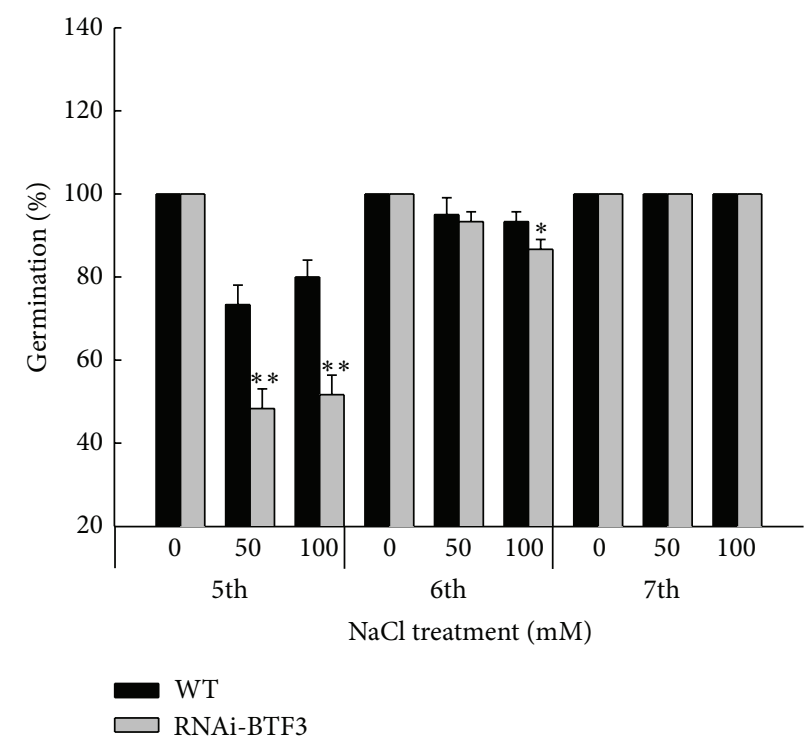

(c)

FIgURE 2: Germination of $O s j 10 g B T F 3^{\mathrm{Ri}}$ lines and wild-type (WT) rice seeds treated with different concentrations of $\mathrm{GA}_{3}$, ABA, and NaCl. Germination readings were taken after 4 th, 5 th, 6 th, 7 th, and 8 th days. Error bars indicate the S.D. $(n=30) .{ }^{*} P \leq 0.05,{ }^{* *} P \leq 0.01$ (Student's $t$-test).

$\mathrm{GA}_{3}$ (Figure 5). For Osj10gBTF3 ${ }^{\mathrm{Ri}}$ lines, the transcript level increased with $\mathrm{GA}_{3}$ concentration both in root and in shoot but the transcript increased by about $50 \%$ in shoot and $100 \%$ in root treated with $100 \mu \mathrm{M} \mathrm{GA}_{3}$, respectively, as compared to controls (Figure 5) and the expression of transcript increased with the increasing concentration of $\mathrm{GA}_{3}$ in both root and shoot (Figure 5). In contrast, the transcript level decreased in both root and shoot with $\mathrm{GA}_{3}$ in $O s j 10 g B T F 3^{\mathrm{Ri}}$ seedling particularly in root at $200 \mu \mathrm{M}$ (Figure 5).

For the ABA treatment, the number of Osj3g1BTF3 transcripts increased with increasing level from 5 to $10 \mu \mathrm{M}$ in the root. However, the level appeared to be significantly decreased in shoot at $5 \mu \mathrm{M}$, after which the expression level increased at $10 \mu \mathrm{M}$ (Figure 6). However, the transcript level decreased in root and shoot of $O s j 10 g B T F 3^{\mathrm{Ri}}$ lines after treatment with $5 \mu \mathrm{M}$ ABA, but the expression level significantly increased in root and shoot at $10 \mu \mathrm{M}$ ABA (Figure 6). In $O s j 3 g 2 B T F 3$, the expression decreased with increasing level of $\mathrm{ABA}$ in the root and the transcript level increased significantly in shoot at $10 \mu \mathrm{M}$ ABA. In $O s j 10 g B T F 3^{\mathrm{Ri}}$ seedling, the expression level significantly decreased in root and shoot with increasing ABA concentration (Figure 6). Similarly, in $O s j 10 g B T F 3$, the expression of transcript increased with increasing concentration of $\mathrm{ABA}$ in the root. However, 


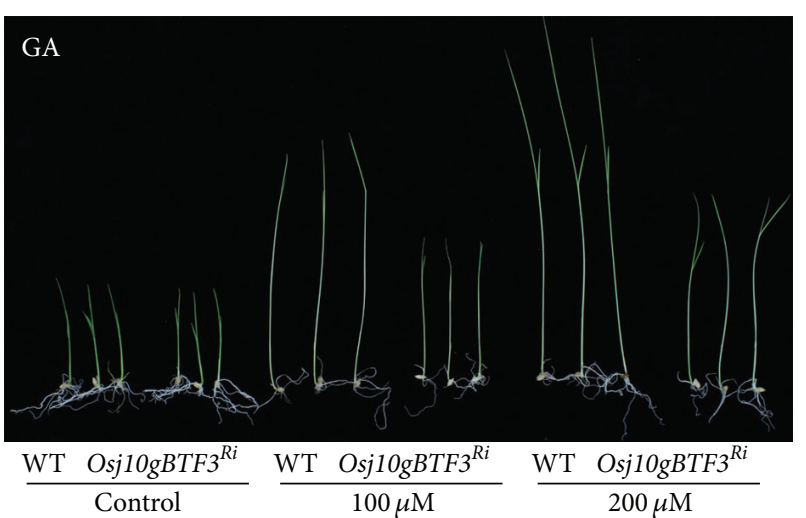

(a)

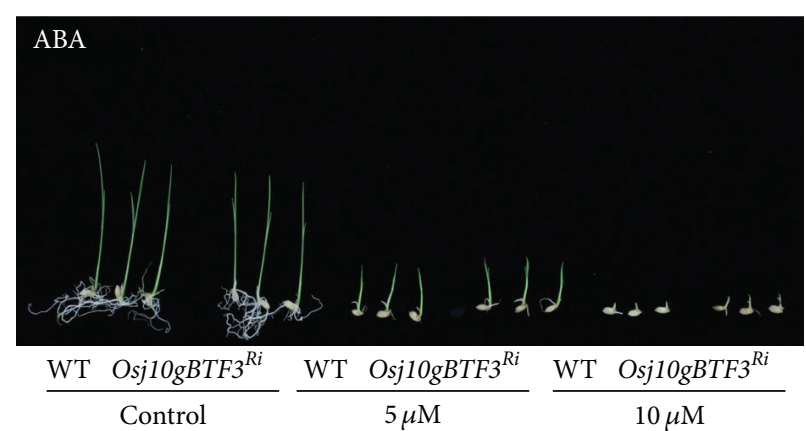

(b)

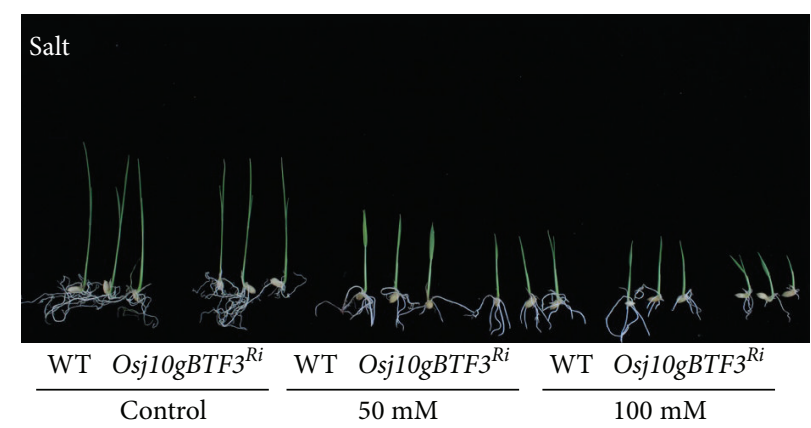

(c)

FIGURE 3: Comparison of $\mathrm{Osj} 10 \mathrm{gBTF} 3^{\mathrm{Ri}}$ lines and wild-type (WT) rice seeds grown under various concentrations of $\mathrm{GA}_{3}$, $\mathrm{ABA}$, and $\mathrm{NaCl}$.

the transcript level did not change significantly in shoot after treatment with ABA. In contrast, the number of transcripts decreased about $50 \%$ with $\mathrm{ABA}$ in $O s j 10 g B T F 3^{\mathrm{Ri}}$ seedling as compared to WT. These results show simply that OsBTF3 expression is mostly constitutive but slightly modulated by $\mathrm{ABA}$ in shoot at higher concentrations.

For salt treatment, the expression level of Osj3g1BTF3 increased with increasing level of salt in the root and shoot particularly at $50 \mathrm{mM}$. In contrast, the transcript level decreased significantly in $O s j 10 g B T F 3^{\mathrm{Ri}}$ seedling at $100 \mathrm{mM}$ $\mathrm{NaCl}$ (Figure 7), but the level of transcript was dramatically decreased about $80 \%$ in root at 50 and $100 \mathrm{mM}$ as compared to control (Figure 7). In Osj3g2BTF3, the transcript level increased in both root and shoot with salt particularly at $50 \mathrm{mM}$; however, in $O s j 10 g B T F 3^{\mathrm{Ri}}$ lines, the level of expression gradually decreased in both root and shoot with increasing concentration as compared with WT (Figure 7). The samples treated with salt significantly upregulated the transcript level of Osj10gBTF3 at $50 \mathrm{mM}$ both in root and in shoot, after which the expression level decreased at $100 \mathrm{mM}$. In Osj10gBTF3 ${ }^{\mathrm{Ri}}$ seedling, the number of transcripts decreased mainly in roots with salt as compared to control (Figure 7). These results show that the downregulation of the BTF3 gene in $O s j 10 g B T F 3^{\mathrm{Ri}}$ seedling may reflect the compromised protein translation and importing activity under salt stress. For hormone treatment, the induction effect showed by ABA was much more effective than the repression effect caused by $\mathrm{GA}_{3}$. There was a difference between the two hormones, indicating that BTF3 is more sensitive to $\mathrm{GA}_{3}$ than $\mathrm{ABA}$.

\section{Discussion}

Recently, it has been documented that BTF3 plays a vital role in plant growth and development [6]. However, there are no reports available about the role of OsBTF3 and how they are regulated by $\mathrm{GA}_{3}, \mathrm{ABA}$, and $\mathrm{NaCl}$ during seed germination and seedling growth. In the present study, BTF3-like gene Osj10gBTF3 was cloned and functionally analyzed and the results may help to understand OsBTF3 protein function more comprehensively.

There are numerous BTF3 genes in rice genomes and in other plant species that are highly similar to each other (Figure 1(a)). The amino acid sequences of different variants of OsBTF3 are similar to other plant species excluding variations in the lengths of the exon and intron. We have observed three signal systems which include important MMTS, NLS, and ERRS in Osj3g1BTF3 and Osj10gBTF3, used to target the correct destination of new synthesized proteins [6]. It has been reported that these specific addressing systems such as MMTS [16], NLS [17], and ERRS [18] have been used by the new synthesized proteins to specifically target the correct destination [19]. A NLS "RRKKK" is putatively positioned between amino acid residues 22-26 in the N-terminal (Figure 5(a)), demonstrating that the OsBTF3 


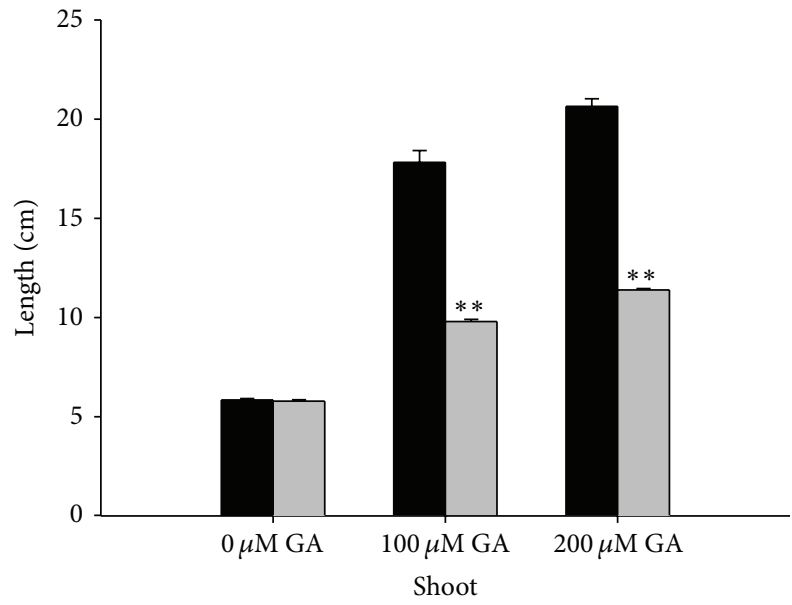

(a)

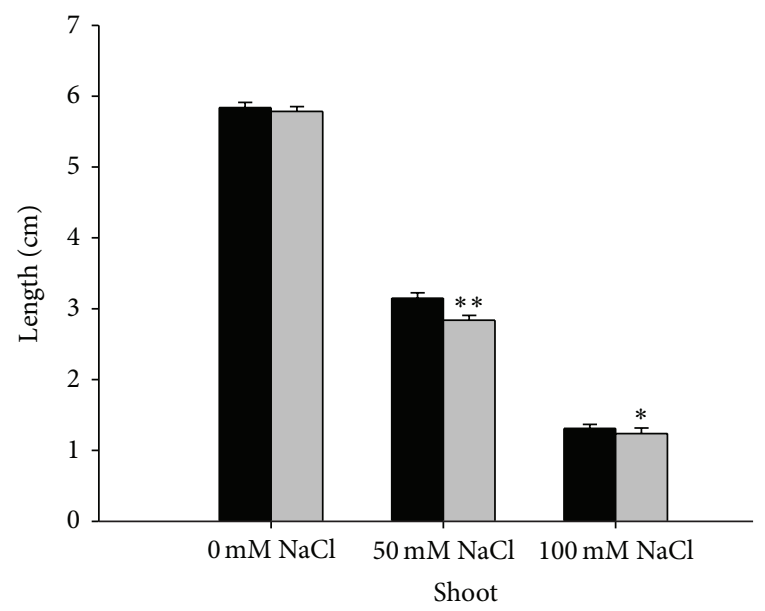

(c)

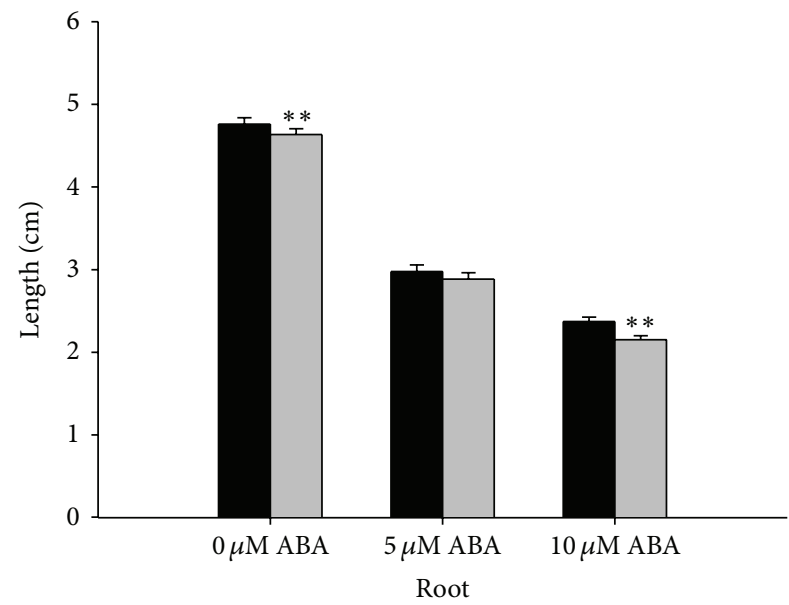

WT

$\square$ RNAi-BTF3

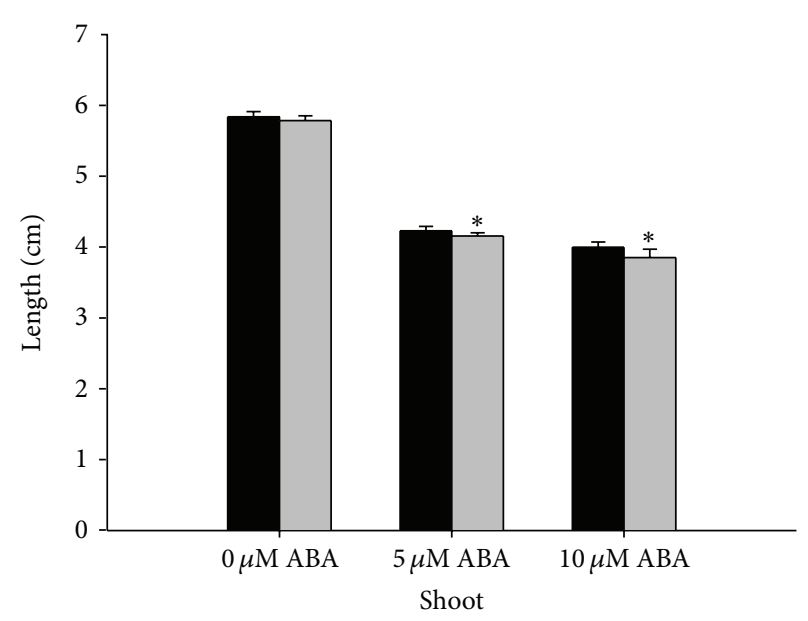

(b)

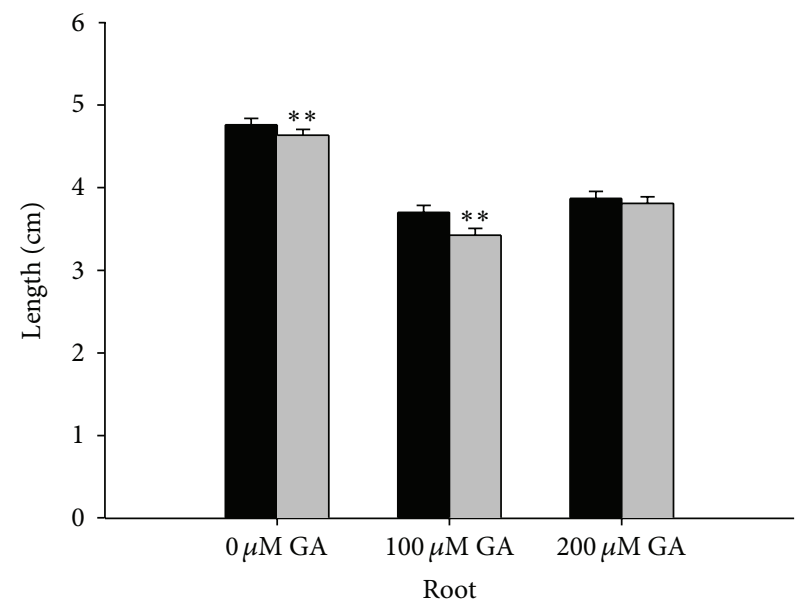

(d)

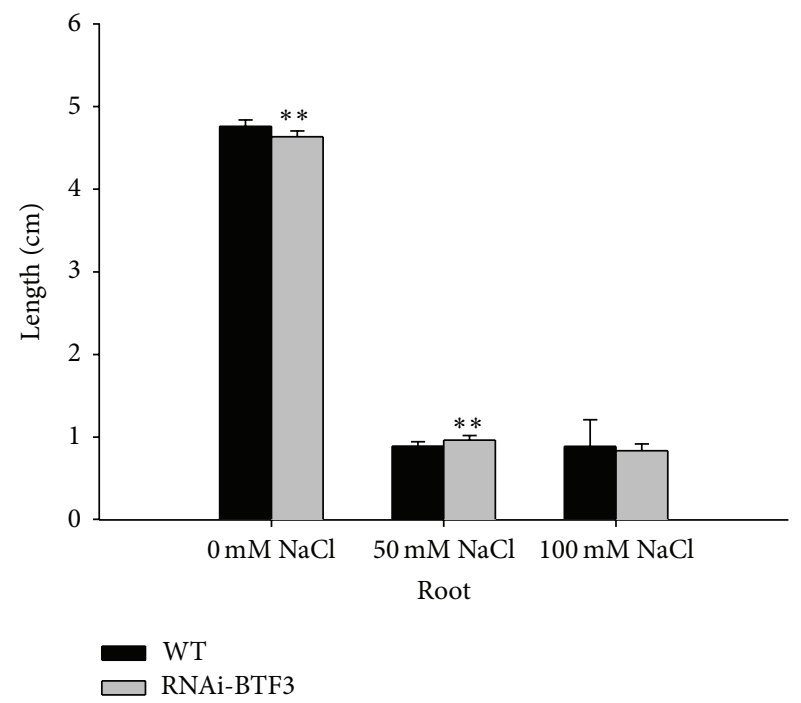

(f)

FIGURE 4: Response of $O s j 10 g B T F 3^{\mathrm{Ri}}$ lines and wild-type (WT) seedlings to different concentrations of $\mathrm{GA}_{3}, \mathrm{ABA}$, and NaCl after $15 \mathrm{~d}$ of germination. Error bars indicate the S.D. $(n=30) .{ }^{*} P \leq 0.05,{ }^{* *} P \leq 0.01$ (Student's $t$-test). 


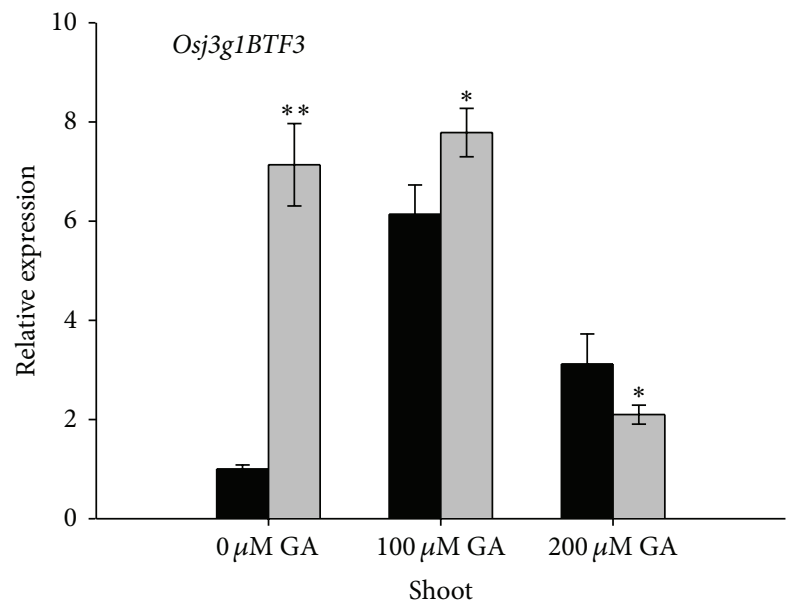

(a)

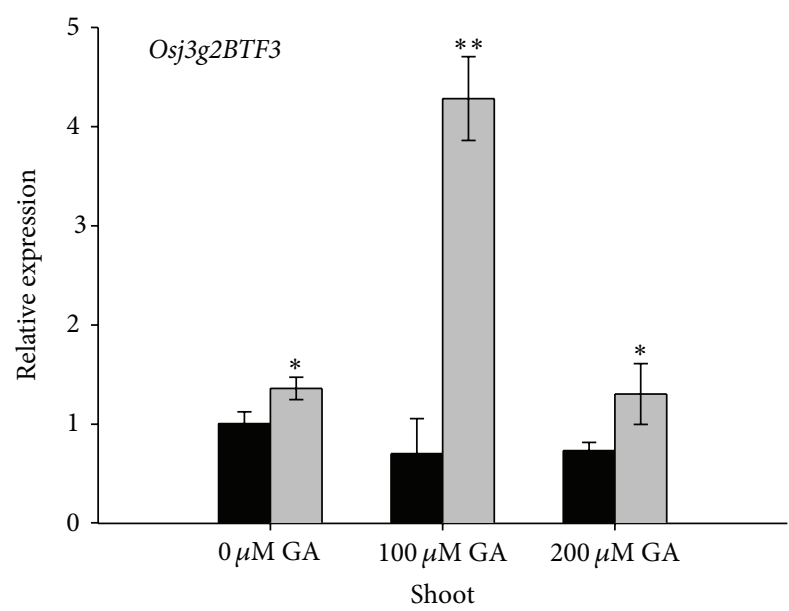

(c)

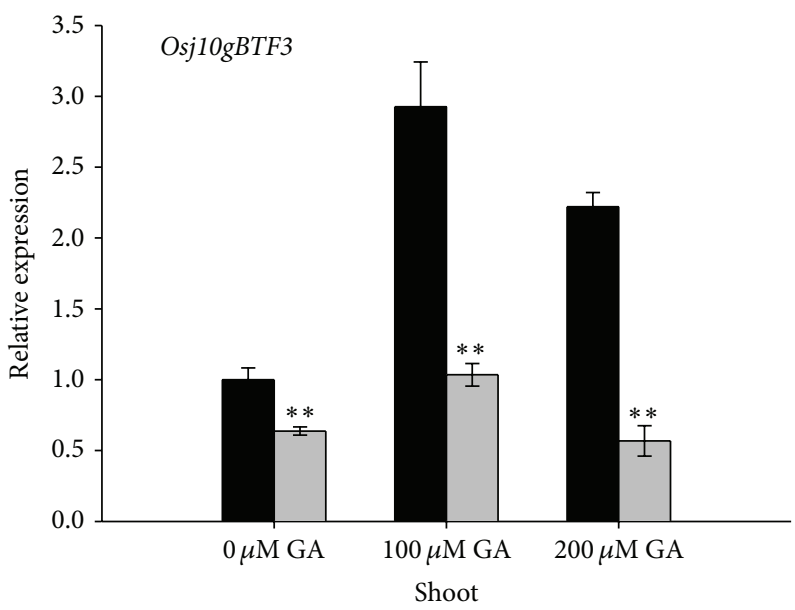

WT

$\varpi$ RNAi-BTF3

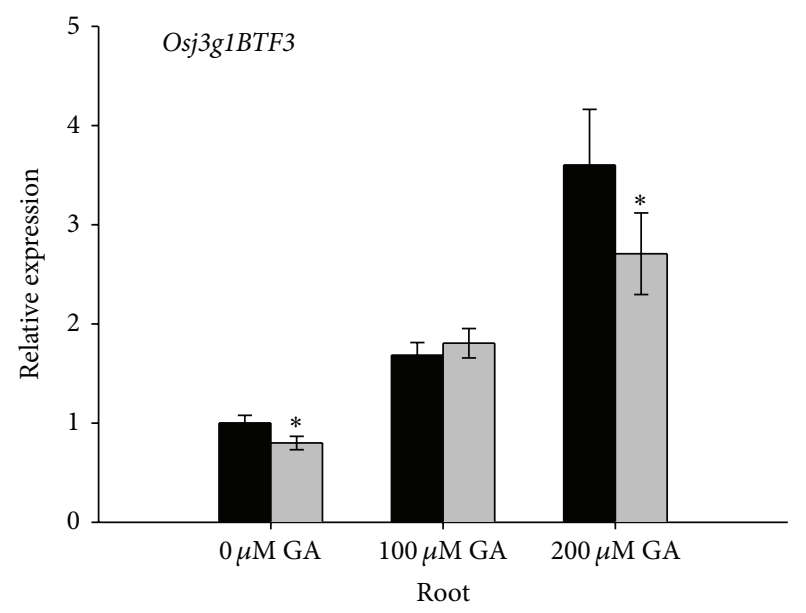

(b)

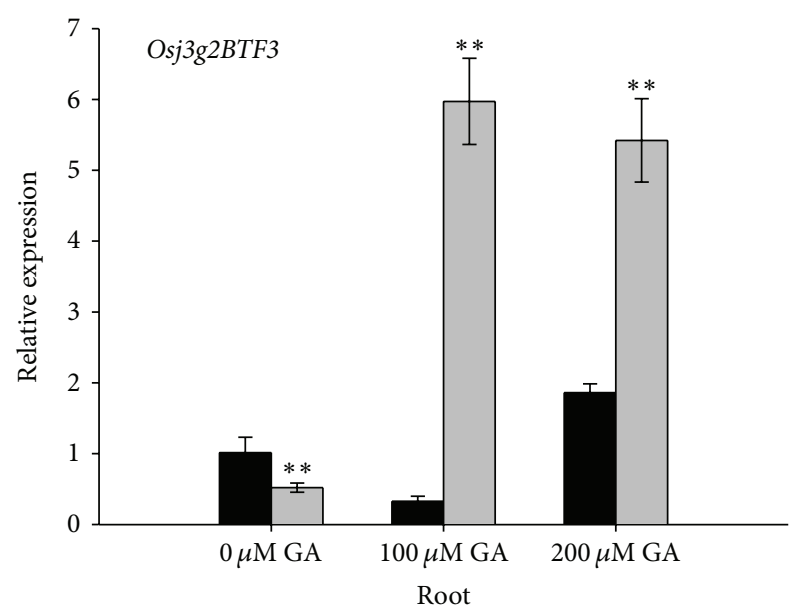

(d)

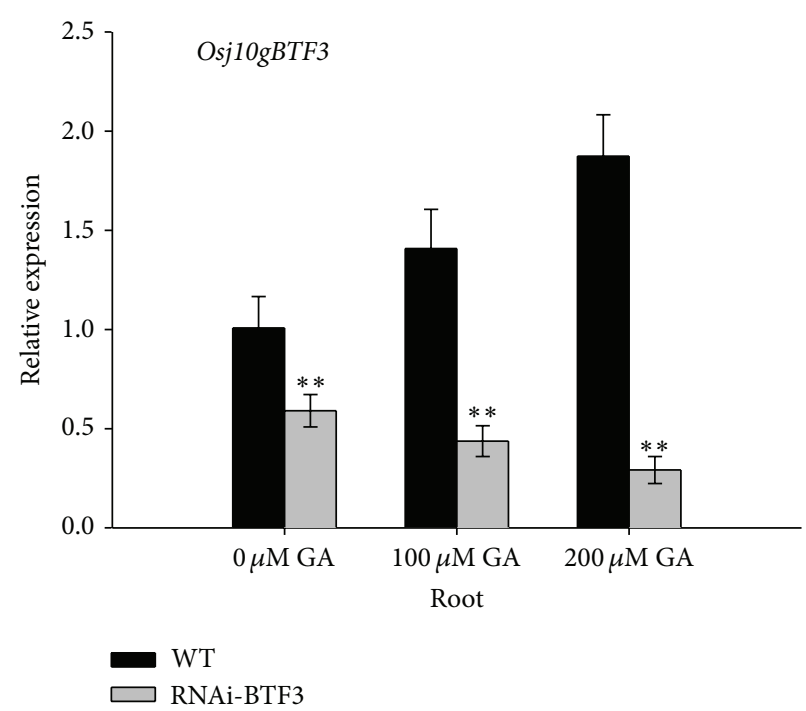

(f)

FigURE 5: The expression analyses of Osj10gBTF3 (LOC_Os10g34180) and its two homologous genes Osj3g1BTF3 (LOC_Os03g01910) and Osj3g2BTF3 (LOC_Os03g63400) in root and shoot of Osj10gBTF3 ${ }^{\mathrm{Ri}}$ lines and wild-type (WT) under different concentrations of $\mathrm{GA}_{3}$. The detection was done based on three independent samples and ubiquitine was used as internal control. 


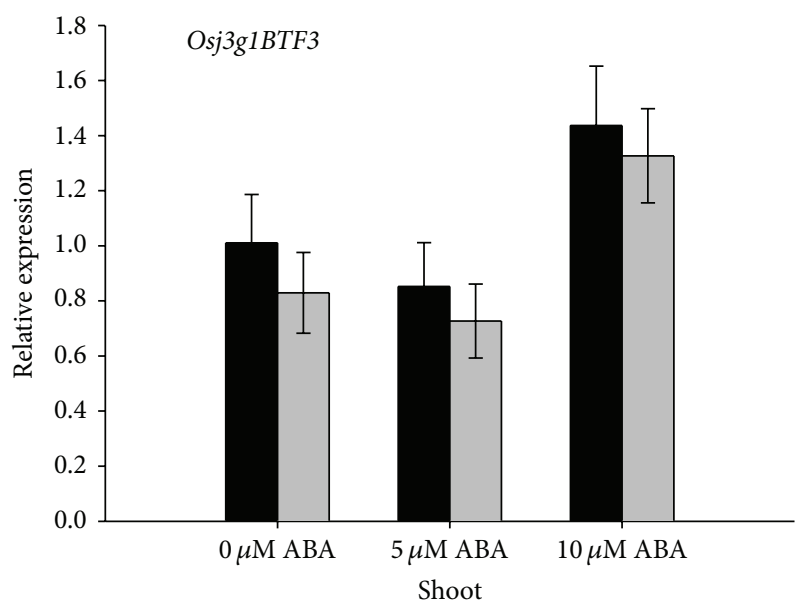

(a)

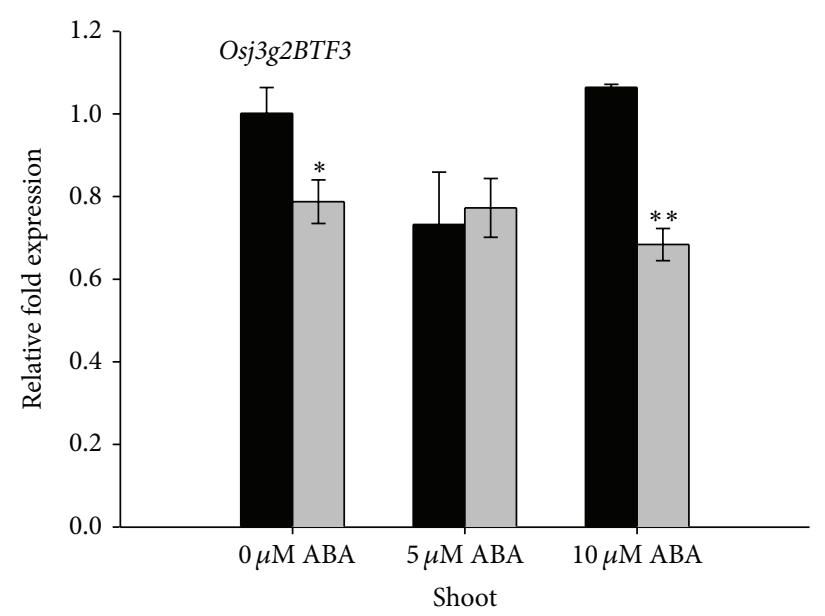

(c)

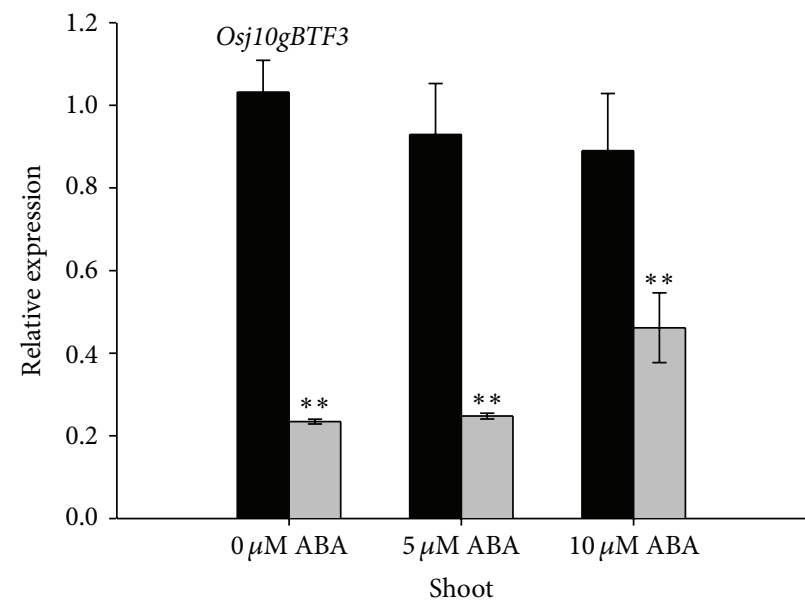

WT
RNAi-BTF3

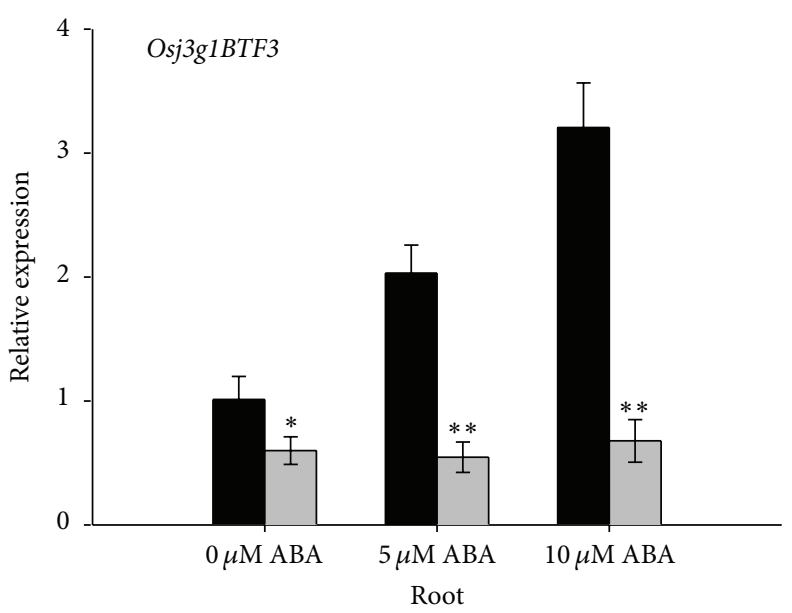

(b)

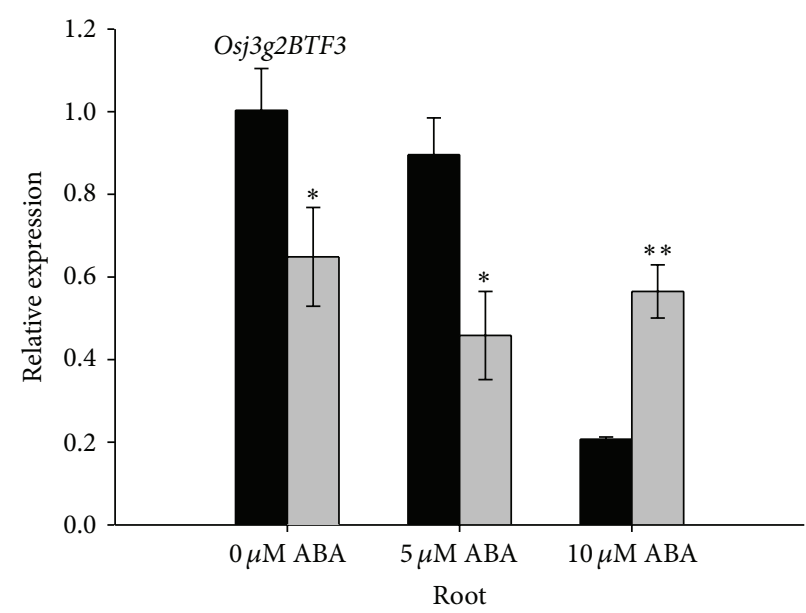

(d)

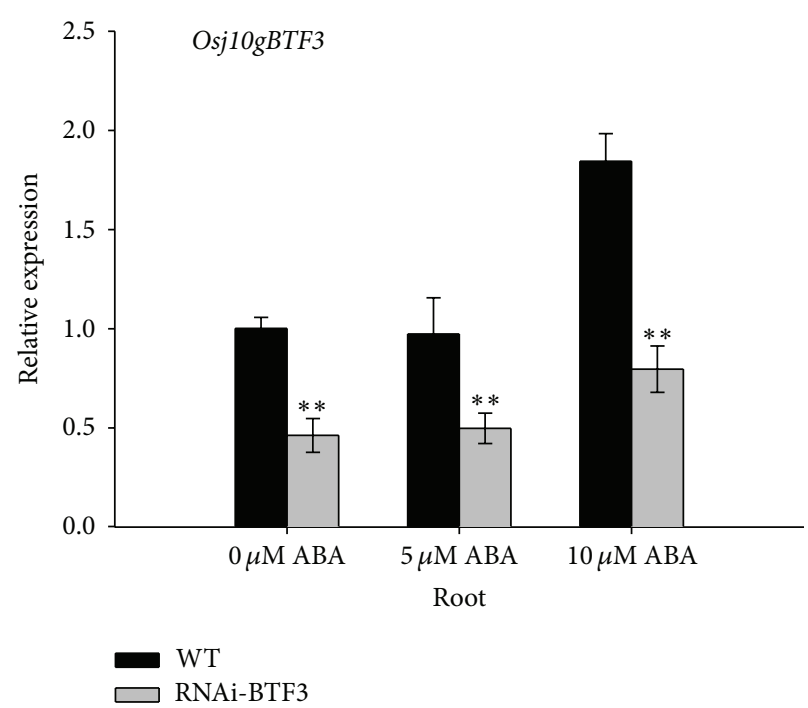

(f)

FIgURE 6: The expression analyses of Osj10gBTF3 (LOC_Os10g34180) and its two homologous genes Osj3g1BTF3 (LOC_Os03g01910) and Osj3g2BTF3 (LOC_Os03g63400) in root and shoot of Osj10gBTF3 ${ }^{\mathrm{Ri}}$ lines and wild-type (WT) under different concentrations of ABA. The detection was done based on three independent samples and ubiquitine was used as internal control. 


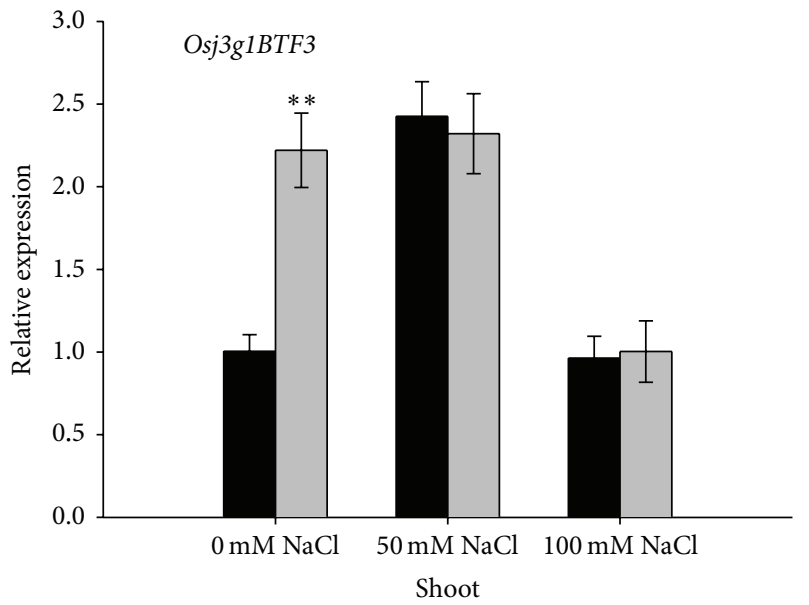

(a)

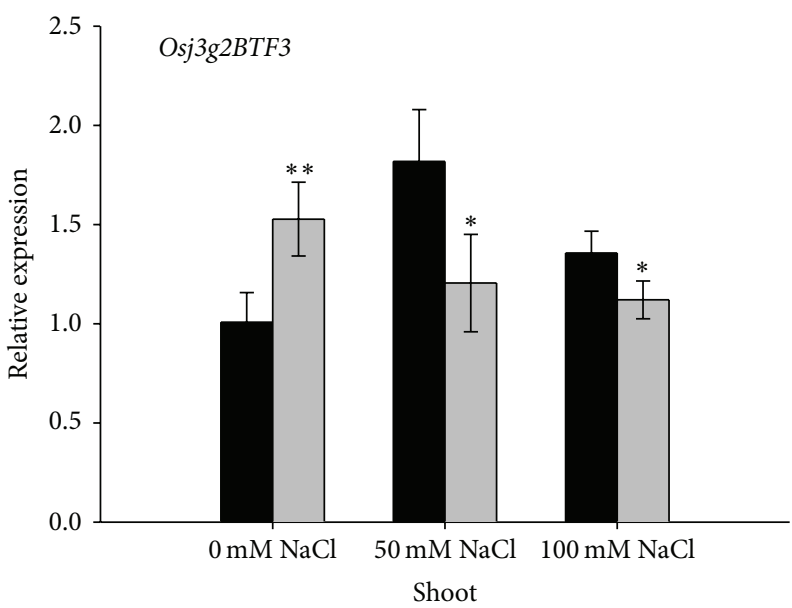

(c)

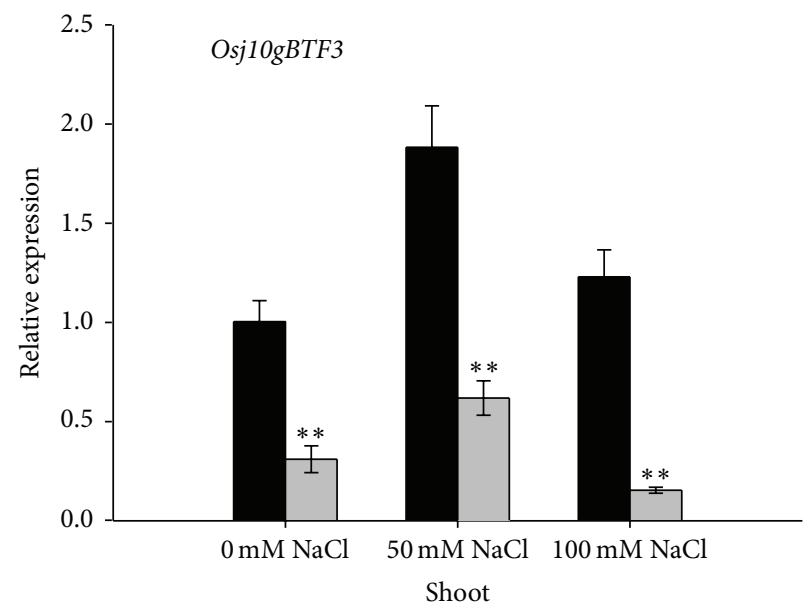

WT

$\square$ RNAi-BTF3

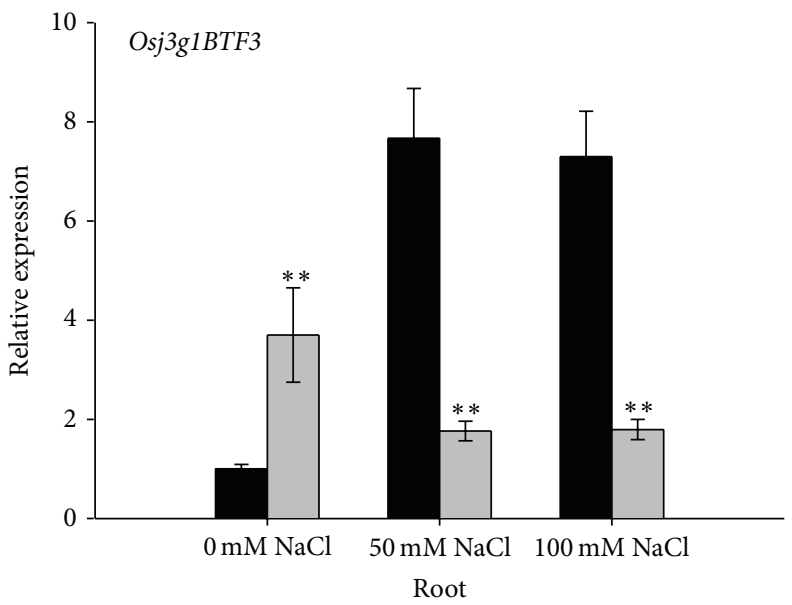

(b)

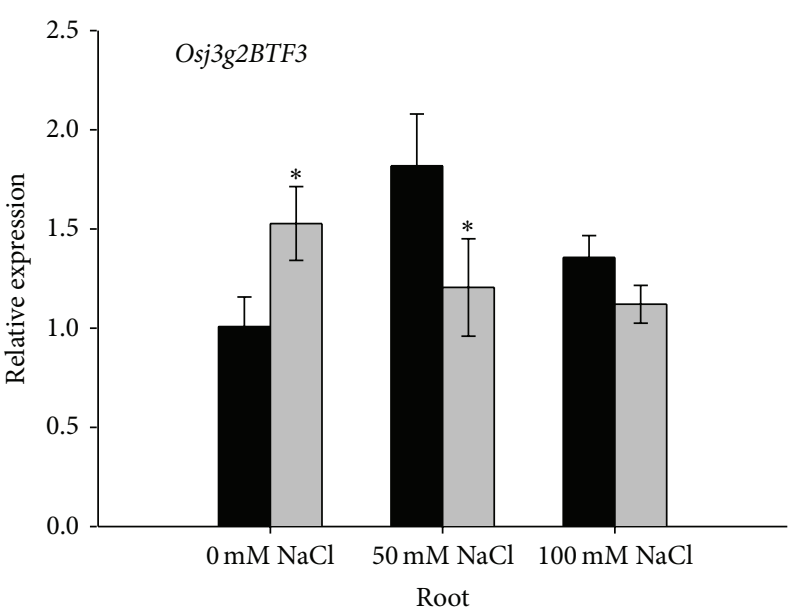

(d)

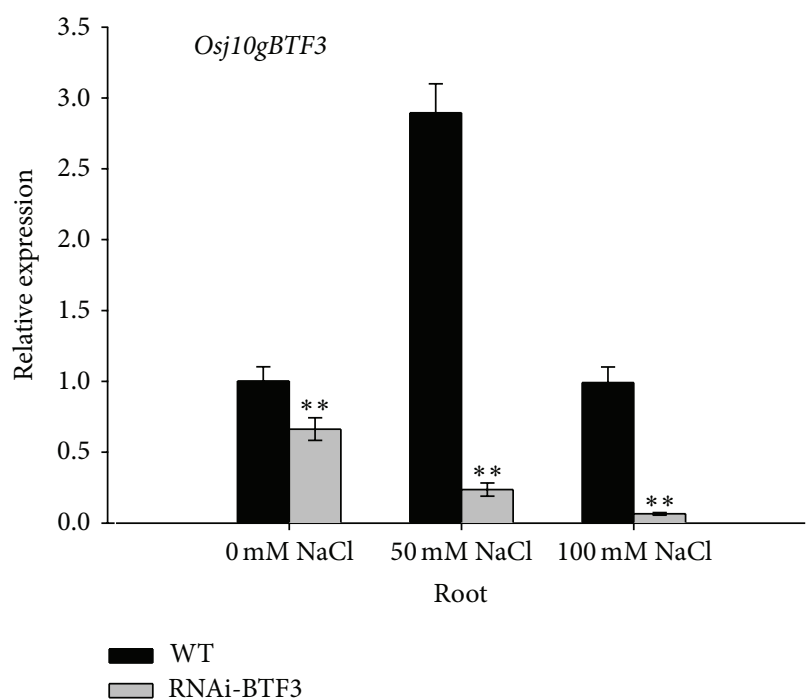

(f)

Figure 7: The expression analyses of Osj10gBTF3 (LOC_Os10g34180) and its two homologous genes Osj3g1BTF3 (LOC_Os03g01910) and Osj3g2BTF3 (LOC_Os03g63400) in root and shoot of Osj10gBTF3 ${ }^{\mathrm{Ri}}$ lines and wild-type (WT) under different concentrations of salt. The detection was done based on three independent samples and ubiquitine was used as internal control. 
protein might be located in both cytoplasmic membrane system and nucleus [6]. It is well established that BTF3 is not only a cytoplasmic membrane protein that functions in the targeting and translocation of nascent polypeptides [20, 21] but may also play an important role in the nucleus, affecting the transcription levels of some genes in rice [22-24].

It was observed that Osj10gBTF3 and Osj3g1BTF3 are probably similar but different from $O s j 3 g 2 B T F 3$ in biological function. To verify this, BTF3-like gene Osj10gBTF3 was cloned and functionally analyzed during seed germination and seedling growth. In the present study, it was observed that the Osj10gBTF3 ${ }^{\mathrm{Ri}}$ lines were sensitive to $\mathrm{GA}_{3}, \mathrm{ABA}$, and $\mathrm{NaCl}$ treatment, particularly to $\mathrm{GA}_{3}$ since their applications did not affect final germination percentage but caused WT seeds to germinate more rapidly than the $O s j 10 g B T F 3^{\mathrm{Ri}}$ transgenic lines, and their mean germination rate decreased with increased concentrations of $\mathrm{GA}_{3}, \mathrm{ABA}$, and $\mathrm{NaCl}$. Similarly, seedling growth was inhibited compared with that of WT control, particularly when treated with 100 or $200 \mathrm{uM}$ $\mathrm{GA}_{3} ; 50 \%$ reduction in shoots were observed in $O s j 10 g B T F 3^{\mathrm{Ri}}$ seedlings (Figure 5). RNAi inhibition of Osj10gBTF3 reduced the expression of Osj10gBTF3 transcripts, as a result reducing the manufacturing of the essential amount of NAC complex for normal plant growth. Hence, once the transcript level of Osj10gBTF3 is decreased, it disturbed the function of this monomeric subunit plus the complete NAC, resulting in severe vegetative defects in $O s j 10 g B T F 3^{\mathrm{Ri}}$ lines [6]. It has been reported that the repression of Osj10gBTF3 caused serious plant growth and development defects [6]. These results are similar to some other studies demonstrating that BTF3 take part in cell cycle regulation via interaction with cyclins [25]. Mutants lacking NAC also showed visible growth and morphological problem in yeast and tobacco $[20,26]$. Furthermore, the inhibition of BTF3 participated in the repression of transcription and protein synthesis in apoptotic K562 cells [27], while change in BTF3 expression is linked with apoptosis in BL60 Burkitt lymphoma cells [28]. On the basis of these results, we can conclude that BTF3 plays an important role in seed germination and seedling growth.

To further verify these results, we observed expression of different variants of OsBTF3 in root and shoot in Osj10gBTF3 ${ }^{\mathrm{Ri}}$ and WT seedlings. We observed that the expression of different variants of OsBTF3 was primarily constitutive, being generally modulated by different $\mathrm{GA}_{3}$, $\mathrm{ABA}$, and salt stress treatments in $O s j 10 g B T F 3^{\mathrm{Ri}}$ and $\mathrm{WT}$ seedlings (Figures 5, 6, and 7). The expression of Osj3g1BTF3 and $O s j 10 g B T F 3$ was induced by low and high concentrations of $\mathrm{GA}_{3}$ and $\mathrm{ABA}$ in root and shoot (Figures 5 and 6), but the transcript level decreased in shoot at high concentrations (Figures 5 and 6). In Osj10gBTF3 ${ }^{\mathrm{Ri}}$ seedling, the transcript level increased both in root and in shoot with increasing $\mathrm{GA}_{3}$ and $\mathrm{ABA}$ concentration, whereas the transcript level of $O s j 10 g B T F 3$ decreased with increasing $\mathrm{GA}_{3}$ concentration (Figures 5 and 6). In Osj3g2BTF3, seedling treated with $100 \mu \mathrm{M} \mathrm{GA}_{3}$ had less transcripts, but the level significantly increases in root at $100 \mu \mathrm{M} \mathrm{GA}_{3}$ (Figure 5), whereas, in $O s j 10 g B T F 3^{\mathrm{Ri}}$ lines, the transcript level increased both in root and shoot with $\mathrm{GA}_{3}$ concentration (Figure 5).
In $O s j 3 g 2 B T F 3$ the transcript levels decreased with increasing level of ABA in the root but increased in shoot at $10 \mu \mathrm{M}$ ABA. In $O s j 10 g B T F 3^{\mathrm{Ri}}$ seedling, the expression level significantly decreased in root and shoot with increasing ABA concentration (Figure 6). Wang et al. [6] observed a 62\% increase in Osj10gBTF3 expression level with ABA, compared to a $22 \%$ reduction with $\mathrm{GA}_{3}$ after treatment with the same concentration for $12 \mathrm{~h}$. In previous reports, it has been observed that the transcript level of $N b B T F 3$ remained unaffected when exposed to $100 \mu \mathrm{M}$ of $\mathrm{ABA}$ and $\mathrm{GA}_{3}$ [26]. Similarly, He et al. [29] did not find any significant change in SmBTF3, when treated with ABA for $24 \mathrm{hrs}$. By using $100 \mu \mathrm{M}$ of ABA to treat maize (Zea mays L.) plants, Zhang et al. [30] found that $Z m B T F 3$ (Zea mays BTF3) expressions were significantly decreased. The salt concentration upregulated Osj3g1BTF3, Osj3g2BTF3, and Osj10gBTF3 expression at $50 \mathrm{mM}$ in both root and shoot, but, in $O s j 10 g B T F 3^{\mathrm{Ri}}$ seedling, the number of transcripts decreased mainly in roots with salt as compared to control (Figure 7). Wang et al. [6] have observed that the expression of Osj10gBTF3 was downregulated under high salt concentration, while low salt concentrations upregulated Osj10gBTF3 expression in rice. Similarly, Li et al. [4] demonstrated that transcript level of OsBTF3 was significantly reduced in rice plants under salt stress and the salt resistance was improved in the seedlings of OsBTF3 transgenic lines. In maize, Zhang et al. [30] observed that expression of BTF3 was downregulated at $250 \mathrm{mM} \mathrm{NaCl}$. In contrast, BTF3 transcript level was significantly increased by salt stress in Suaeda asparagoides [31], while expression level of SabBTF3 was differentially regulated by various abiotic stresses, such as drought, salinity, ABA, and temperature in roots [7]. These results also suggested that Osj3g1BTF3 and Osj10gBTF3 are much similar in their response to $\mathrm{GA}_{3}, \mathrm{ABA}$, and $\mathrm{NaCl}$ during seedling stage.

This is a first report demonstrating the involvement of different variants of BTF3 in seed germination and seedling stage. It was observed that Osj3g1BTF3 and Osj10gBTF3 are a similar type of genes which plays an important role in plant growth, especially in seed germination and seedling growth. Functional analysis revealed that both of these genes are much similar in biological functions. Further investigation is required to provide the insight into the functions of BTF3 and the connected mechanisms responsible for improving abiotic stress tolerance in plants.

\section{Conflict of Interests}

The authors declare that there is no conflict of interests regarding the publication of this paper.

\section{Authors' Contribution}

Wenyi Wang and Muhammad Jamil contributed equally to this work.

\section{Acknowledgment}

This work was financially supported by the China Postdoctoral Science Foundation (Grant no. 2013M541788). 


\section{References}

[1] M. L. Zhou, J. T. Ma, J. F. Pang, Z. L. Zhang, Y. X. Tang, and Y. M. Wu, "Regulation of plant stress response by dehydration responsive element binding (DREB) transcription factors," African Journal of Biotechnology, vol. 9, no. 54, pp. 9255-9279, 2010.

[2] S. S. Hussain, M. A. Kayani, and M. Amjad, "Transcription factors as tools to engineer enhanced drought stress tolerance in plants," Biotechnology Progress, vol. 27, no. 2, pp. 297-306, 2011.

[3] G. X. Li, M. S. Wu, and C. Y. He, "Gene expression response of transcription factor OsBTF3 in rice to bacterial and fungal infection and signal molecule treatment revealed by quantitative real-time PCR analysis," Acta Phytopathologia Sinica, vol. 39, no. 3, pp. 272-277, 2009.

[4] G. X. Li, M. S. Wu, and C. Y. He, "Resistance to high salt and cold stress of transgenic rice seedlings with over-expressed and RNAi-silenced OsBTF3," Chinese Journal of Rice Science, vol. 26, no. 1, pp. 5-8, 2012.

[5] M. Gorantla, P. R. Babu, V. B. R. Lachagari, F. A. Feltus, A. H. Paterson, and A. R. Reddy, "Functional genomics of drought stress response in rice: transcript mapping of annotated unigenes of an indica rice (Oryza sativa L. cv. Nagina 22)," Current Science, vol. 89, no. 3, pp. 496-514, 2005.

[6] Y. Wang, X. Zhang, S. Lu et al., "Inhibition of a basal transcription factor 3-like gene Osj10gBTF3 in rice results in significant plant miniaturization and typical pollen abortion," Plant and Cell Physiology, vol. 53, no. 12, pp. 2073-2089, 2012.

[7] R. Karan and K. S. Prasanta, "Overexpression of a nascent polypeptide associated complex gene (SabNAC) of Spartina alterniflora improves tolerance to salinity and drought in transgenic Arabidopsis," Biochemical and Biophysical Research Communications, vol. 424, no. 4, pp. 747-752, 2012.

[8] G. X. Li, H. M. Chen, M. S. Wu, and C. Y. He, "Functions of OsBTF3 gene in regulation of photosynthesis, growth and development in rice," Acta Agronomica Sinica, vol. 38, no. 5, pp. 904-908, 2012.

[9] X. M. Zheng, D. Black, P. Chambon, and J. M. Egly, "Sequencing and expression of complementary DNA for the general transcription factor BTF3," Nature, vol. 344, no. 6266, pp. 556-559, 1990.

[10] B. Beatrix, H. Sakai, and M. Wiedmann, "The alpha and beta subunit of the nascent polypeptide-associated complex have distinct functions," Journal of Biological Chemistry, vol. 275, no. 48, pp. 37838-37845, 2000.

[11] B. Wiedmann, H. Sakai, T. A. Davis, and M. Wiedmann, "A protein complex required for signal-sequence-specific sorting and translocation," Nature, vol. 370, no. 6489, pp. 434-440, 1994.

[12] M. A. Freire, "Translation initiation factor (iso) $4 \mathrm{E}$ interacts with BTF3, the beta subunit of the nascent polypeptideassociated complex," Gene, vol. 345, no. 2, pp. 271-277, 2005.

[13] H. Z. Ma, G. Q. Liu, C. W. Li, G. Z. Kang, and T. C. Guo, "Identification of the TaBTF3 gene in wheat (Triticum aestivum $\mathrm{L}$.) and the effect of its silencing on wheat chloroplast, mitochondria and mesophyll cell development," Biochemical and Biophysical Research Communications, vol. 426, no. 4, pp. 608-614, 2012.

[14] S. U. Huh, K. J. Kim, and K. H. Paek, "Capsicum annuum basic transcription factor 3 (CaBtf3) regulates transcription of pathogenesis-related genes during hypersensitive response upon Tobacco mosaic virus infection," Biochemical and Biophysical Research Communications, vol. 417, no. 2, pp. 910-917, 2012.

[15] K. J. Livak and T. D. Schmittgen, "Analysis of relative gene expression data using real-time quantitative PCR and the $2^{-\Delta \Delta C_{T}}$ method," Methods, vol. 25, no. 4, pp. 402-408, 2001.

[16] M. Kiebler, K. Becker, N. Pfanner, and W. Neupert, "Mitochondrial protein import: specific recognition and membrane translocation of preproteins," Journal of Membrane Biology, vol. 135, pp. 191-207, 1993.

[17] D. Kalderon, B. L. Roberts, W. D. Richardson, and A. E. Smith, "A short amino acid sequence able to specify nuclear location," Cell, vol. 39, no. 3, pp. 499-509, 1984.

[18] C. Itin, F. Kappeler, A. D. Linstedt, and H.-P. Hauri, "A novel endocytosis signal related to the KKXX ER-retrieval signal," The EMBO Journal, vol. 14, no. 10, pp. 2250-2256, 1995.

[19] M. G. Claros and P. Vincens, "Computational method to predict mitochondrially imported proteins and their targeting sequences," European Journal of Biochemistry, vol. 241, no. 3, pp. 779-786, 1996.

[20] R. George, T. Beddoe, K. Landl, and T. Lithgow, “The yeast nascent polypeptide-associated complex initiates protein targeting to mitochondria in vivo," Proceedings of the National Academy of Sciences of the United States of America, vol. 95, no. 5, pp. 2296-2301, 1998.

[21] U. Funfschilling and S. Rospert, "Nascent polypeptideassociated complex stimulates protein import into yeast mitochondria," Molecular Biology of the Cell, vol. 10, no. 10, pp. 3289-3299, 1999.

[22] M. R. Parthun, D. A. Mangus, and J. A. Jaehning, "The EGD1 product, a yeast homolog of human BTF3, may be involved in GAL4 DNA binding," Molecular and Cellular Biology, vol. 12, no. 12, pp. 5683-5689, 1992.

[23] G. Z. Hu and H. Ronne, "Yeast BTF3 protein is encoded by duplicated genes and inhibits the expression of some genes in vivo," Nucleic Acids Research, vol. 22, no. 14, pp. 2740-2743, 1994.

[24] S. Rospert, Y. Dubaquie, and M. Gautschi, "Nascentpolypeptide-associated complex," Cellular and Molecular Life Sciences, vol. 59, no. 10, pp. 1632-1639, 2002.

[25] B. Cooper, X. Hutchison, S. Park et al., "Identification of rice (Oryza sativa) proteins linked to the cyclin-mediated regulation of the cell cycle," Plant Molecular Biology, vol. 53, no. 3, pp. 273279, 2003.

[26] K. S. Yang, H. S. Kim, U. H. Jin et al., "Silencing of NbBTF3 results in developmental defects and disturbed gene expression in chloroplasts and mitochondria of higher plants," Planta, vol. 225, no. 6, pp. 1459-1469, 2007.

[27] R. Li, X. L. Liu, Q. F. Du, S. Zhang, R. C. Luo, and S. Y. Zhou, "Proteome analysis of apoptotic K562 cells induced by harring to-nine," Zhonghua Xue Ye Xue Za Zhi, vol. 25, no. 6, pp. 323327, 2004.

[28] E. Brockstedt, A. Otto, A. Rickers, K. Bommert, and B. Wittmann-Liebold, "Preparative high-resolution two-dimensional electrophoresis enables the identification of RNA polymerase B transcription factor 3 as an apoptosis- associated protein in the human BL60-2 Burkitt lymphoma cell line," Journal of Protein Chemistry, vol. 18, no. 2, pp. 225-231, 1999.

[29] M. He, X. Wu, and Z. Z. Wang, "Cloning and bioinformatics analysis of BTF3 gene from Salvia miltiorrhiza Bunge," Journal of Wuhan Botanical Research, vol. 27, no. 6, pp. 582-588, 2009.

[30] Z. B. Zhang, D. F. Zhang, H. Y. Li et al., "Isolation and expression analysis of a drought-induced gene ZmBTF3b in Maize (Zea 
mays L.)," Scientia Agricultura Sinica, vol. 43, pp. 3280-3287, 2010.

[31] S. Ayarpadikannan, E. Chung, C. W. Cho et al., "Exploration for the salt stress tolerance genes from a salt-treated halophyte, Suaeda asparagoides," Plant Cell Reports, vol. 31, no. 1, pp. 35-48, 2012. 

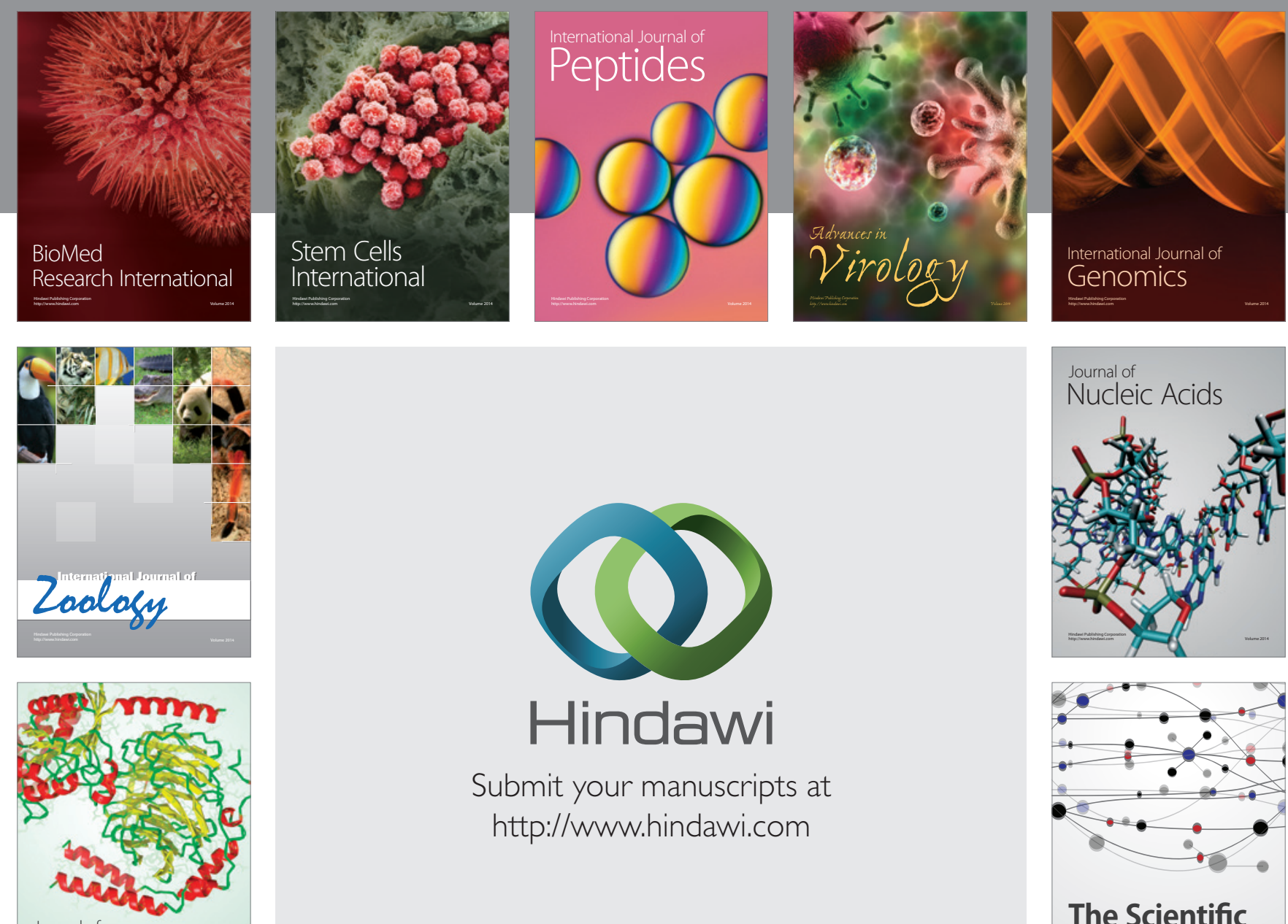

Submit your manuscripts at

http://www.hindawi.com

Journal of
Signal Transduction
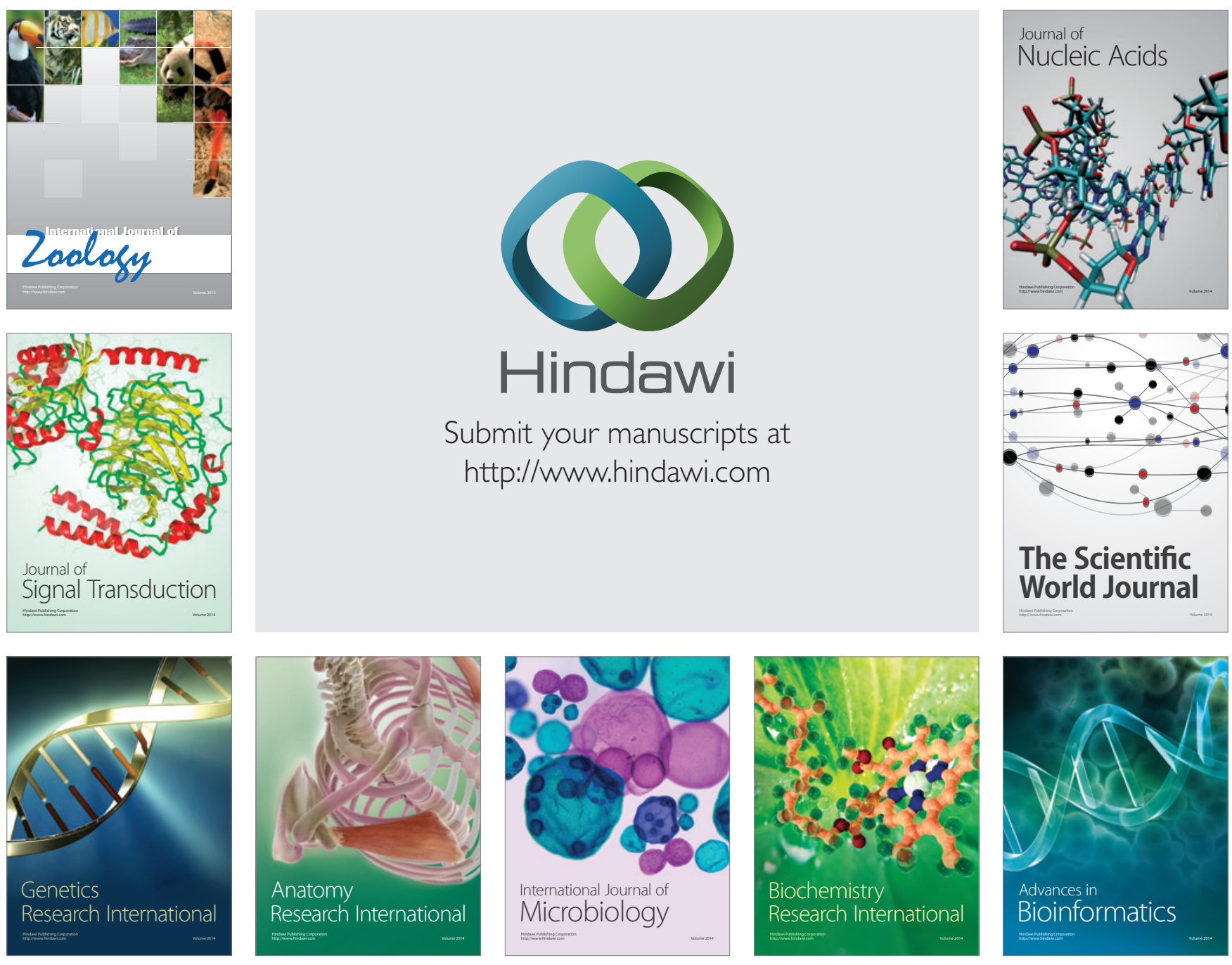

The Scientific World Journal
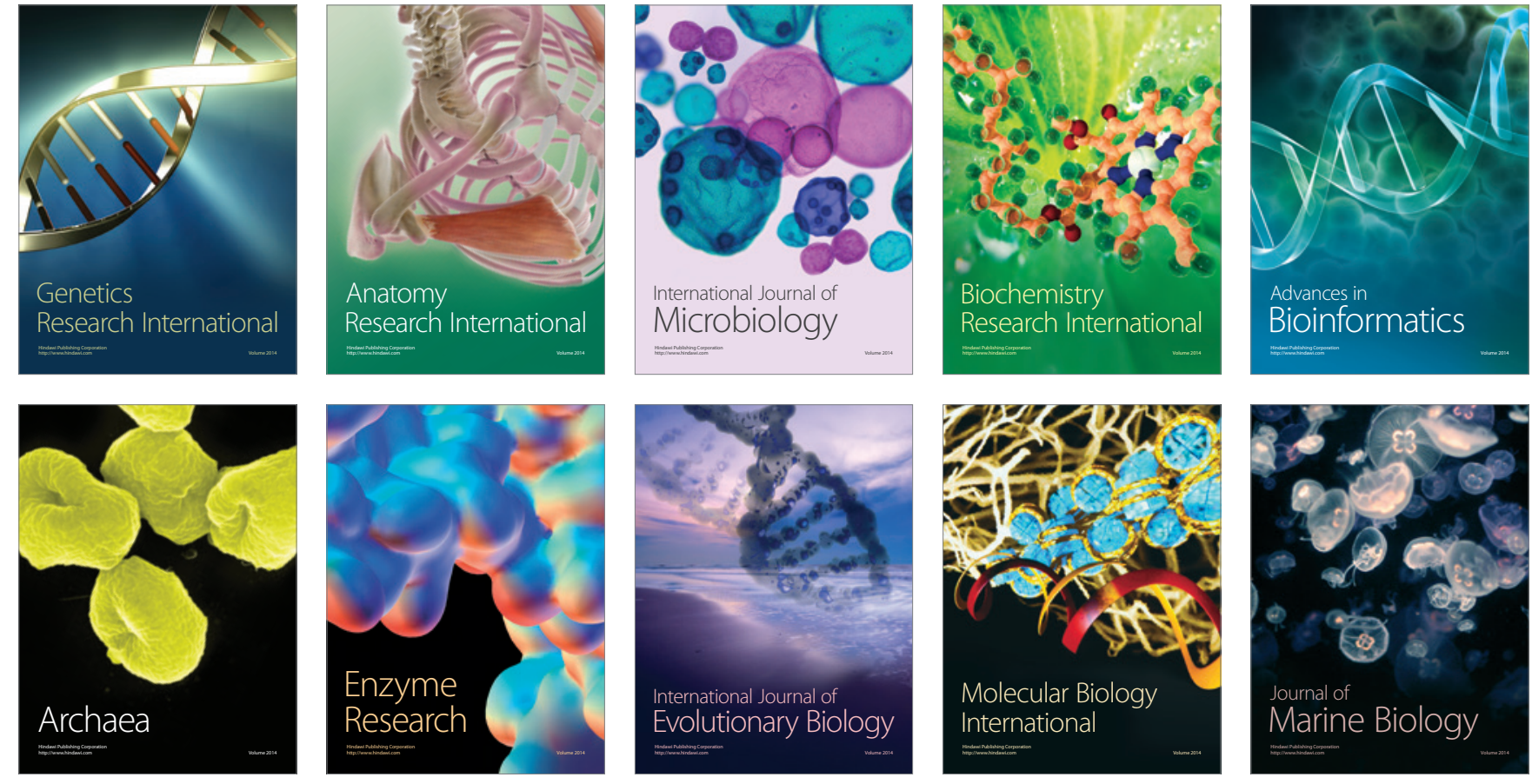